\title{
Opportunities for sensing systems in mining
}

\author{
Michail. E. Kiziroglou, Senior Member, IEEE, David E. Boyle, Member, IEEE, Eric M. Yeatman, \\ Fellow, IEEE and Jan. J. Cilliers
}

\begin{abstract}
Pervasive sensing - the capability to deploy large numbers of sensors, to link them to communication networks, and to analyze their collective data - is transforming many industries. In mining, networked sensors are already used for remote operation, automation including driverless vehicles, health and safety, and exploration. In this paper, the state-of-the-art sensing and monitoring technologies are assessed as solutions against the main challenges and opportunities in the mining industry. Localization, mapping, remote operation, maintenance and health and safety are identified as the main beneficiaries, from rapidly developing technologies such as 3D visualization, augmented reality, energy autonomous sensor nodes, distributed sensing, smart network protocols and big data analytics. It is shown that the identification and management of ore grade in particular, which transcends each stage of the mining process, may critically benefit from certain arising sensing technologies, where major efficiency improvements are possible in exploration, extraction, haulage and processing activities.
\end{abstract}

Index Terms-Mining, Sensors.

\section{INTRODUCTION}

$\mathrm{S}$ ENSOR use is already widespread in mining, including in applications such as automation and remote operation, and data analytics for control and optimization.

The scope of this work is to identify and present sensing technologies that will become profitable to implement within the next 10 years. It includes a compact review of sensing systems that are currently in place, and an outline of upcoming sensing services in mining. Then, it proceeds to an assessment of new and emerging sensing technologies against the current challenges faced by the mining industry, including an evaluation of maturity for short and medium term adoption.

In Section II, the main sensing applications in mining today are overviewed, including the technologies and methods that support them, and indications of recent and anticipated developments that can enhance these applications. These applications include localization and tracking, imaging, 3D ranging and mapping, machine and equipment condition monitoring, composition measurement, exploration, health and safety and tire-pressure monitoring. Then, in section III, an

Manuscript received March 01, 2016; revised July 25, 2016; accepted November 25, 2016. Date of publication ...

Copyright (c) 2015 IEEE. Personal use of this material is permitted. However, permission to use this material for any other purposes must be obtained from the IEEE by sending a request to pubs-permissions@ieee.org.

M. E. Kiziroglou, D. E. Boyle and E. M. Yeatman are with the department of Electrical and Electronic Engineering, Imperial College London, SW7 2BT, U.K. (e-mail: m.kiziroglou@ic.ac.uk)

J. J. Cilliers is with the department of Earth Science and Engineering, Imperial College London, SW7 2BT, U.K. outlook on sensing technologies that are becoming profitable to implement in mining is presented, with an analysis of anticipated impact on the operating method in the mining industry. Through this analysis, key sensing technologies that are desirable in mining applications are identified.

\section{SENSOR APPLICATIONS IN MINING}

\section{A. Localization and Tracking}

A variety of sensor technologies today concern the detection, tracking and communication of relative and absolute position of humans but also vehicles, equipment and other resources. In mining, such technologies are of significant interest mainly in driverless vehicle control, remote operation of equipment and also asset management and tracking, site security and personnel location. The main types of such sensor systems are satellite (GPS) and terrestrial (radio frequency based) positioning systems, dead reckoning systems (inertial sensor based position tracking), beacon sensors, and tagging technology.

\section{1) Driverless vehicle technology:}

The mining industry has been employing driverless vehicles for several years, enabling cost reduction and safety improvements in transport [1]. Local sensing and control has provided increased autonomy to vehicles, which can now operate continuously and feature various supporting features such as route and location optimization, collision avoidance and maintenance control. Recently, the combination of local (proximity) and remote (positioning) sensing has led to increased reliability of such systems. Capabilities such as realtime machine tracking, scheduling, assignment and productivity management are also becoming available [2].

Anticipated developments in this area mainly derive from the rapid development of Advanced Driver Assistance Systems (ADAS) for passenger cars. These systems provide an increasing range of functions including navigation, collision avoidance, parking assistance and self-parking, lane change assistance and adaptive cruise control. Because of the variety of requirements, these systems also integrate ultrasound and LIDAR sensors. Mining automation is expected to benefit from the enhancement and cost reduction of these systems in the automotive market, including not only sensors but the related software for functional integration. The result will be a much richer mix of sensor data from vehicle automation, and more precise and reliable control. The availability of fleet-level data will also allow high-level process optimization, taking advantage of stochastic data analysis techniques for vehicle maintenance [3] and supply chain management [4]. A comparison between the localization and driving sensors used in passenger cars and mining haul trucks is presented in Fig. 1. 

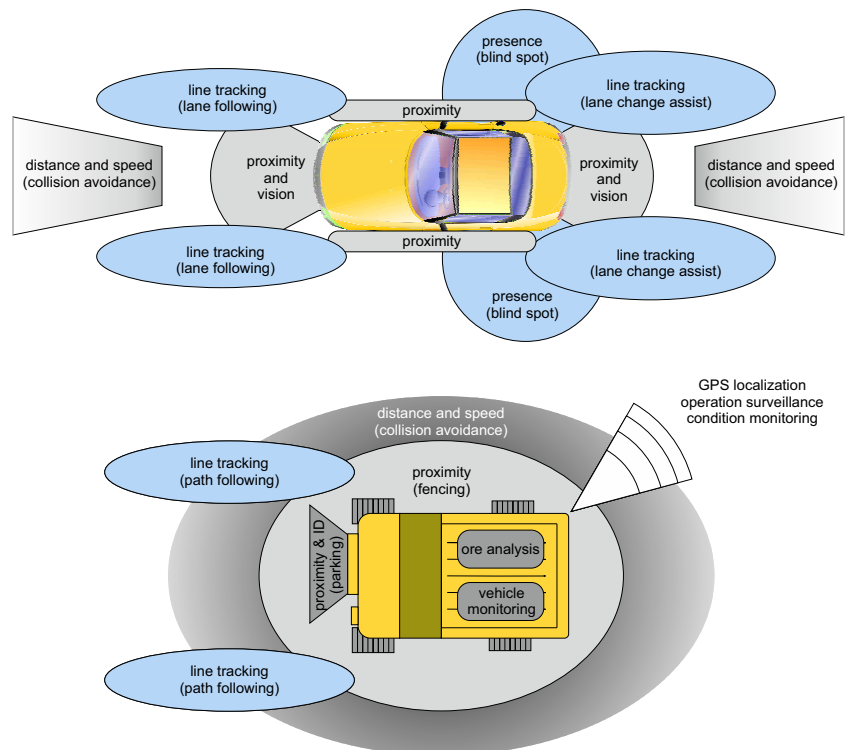

Fig. 1: Schematic description of driving sensors used in passenger vehicles (top) and mining haul trucks (bottom).

\section{2) $R F$ Positioning:}

Real time global positioning has been supporting localization and tracking in mining for decades. A terrestrial receiver can determine its position from a known code sequence coming from four or more satellites of known location, using the synchronization-determined time of flight and the time of transmission and satellite location, which are also included in each signal. The two systems currently in service are GPS and GLONASS, each providing an accuracy of around $5 \mathrm{~m}$. Currently, they are becoming more accurate, mainly by employing secondary receivers in fixed locations. A commercial example of such hybrid systems is the assistedGPS service found in most smartphone products. Also, the Chinese BeiDou and European Galileo systems are expected to provide $\mathrm{cm}$-scale absolute positioning as a commercial service. It is expected that $\mathrm{cm}$-accurate outdoor global positioning will be used routinely in mining operations within 3-5 years.

For indoor locations, local implementations of RF positioning are available, based on a similar working principle In recent advances of such systems, an ultra-wideband real-time tracking system has been adopted by NASA and proposed for various applications, including navigation in mining sites, with features such as high precision, scalability and (optional) dual communication [5]. In the case of brief off-line periods, these systems are often able to estimate position from the last known position and kinematic state, and subsequent estimation of displacement by local tracking of acceleration and orientation. This technique is known as dead reckoning. Combined RF and inertial sensor systems for mining applications have already been proposed [6]. Purely inertial positioning systems are also possible, especially for applications where a known check-point can be visited regularly. As underground operations become more automated, indoor positioning with off-line capability will become increasingly important. Therefore, it is anticipated that the use of dead reckoning in mining will increase greatly in the following few years.
Further possible applications of such positioning systems could include automatically operating shovels and robotic arms. An example of such an initiative can be found in the recent Scanning Range Sensor program of CRC mining, where range sensors are evaluated on-site for mining shovel control [7]. Patents on shovel local orientation and alignment have also been recently disclosed, e.g. [8].

\section{3) Beacon and RFID sensors}

Location beacon systems are currently used in mining monitoring for cave tracking. Ore locations are marked by beacons, to monitor the flow during mining activities, in order to predict waste ingress into the ore. This real-time cave motion monitoring technology can in turn enable cave design optimization. The current state of art involves large-scale beacons, emitting a rotating magnetic field. Their location can be determined by a stationary detector [9].

Beacon systems can also be used for local positioning, by providing proximity information, check-points or fencing of particular areas. An example of such a system can be found in the introduction of RF beacons into consumer electronics wireless devices for indoor positioning [10]. In these applications, low power operation and energy efficiency are key requirements, and hence recently developed communication protocols, such as Bluetooth Low Energy, have been adopted.

A similar positioning principle can also be achieved using RFID tags. A moving object can be tracked by a local RFID reader, at a range of several meters for passive tags, or at a range of several tens of meters for active (battery-powered) tags. Inversely, a moving object equipped with an RFID reader can track its own position by identifying passive or active tag check-points of known location [11]. RFID based beacon solutions have the primary advantage of allowing very large numbers of tags at minimal cost.

\section{4) Proximity sensors}

Proximity sensors can also be used for positioning and tracking, either as stand-alone systems or in tandem with other positioning technologies. They are usually short range sensors and their current use in mining operation is mainly related to position and orientation control of automated equipment such as driverless vehicles, including collision avoidance and personnel security. In orientation control, proximity switches and scanning systems operate alongside central positioning systems (terrestrial RF, GPS etc.), offering complementary information that enhances accuracy, speed and reliability in related automation. In collision avoidance, proximity sensors are used to detect and prevent dangerous situations such as unsafe machine-to-machine and machine-to-personnel distances and unauthorized presence. The main proximity sensor technologies are based on inductive, capacitive, electromagnetic, ultrasonic and optical operating principles. The inductive and capacitive proximity sensors detect the disturbance of a magnetic and electrostatic field respectively, by the close presence of an object. Therefore, they operate at close-proximity, typically below $100 \mathrm{~mm}$. Electromagnetic, ultrasonic and optical proximity sensors offer long-range detection and could potentially provide further critical 
TABLE I

LOCALIZATION TECHNOLOGIES IN MiNING

\begin{tabular}{|c|c|c|c|}
\hline $\begin{array}{l}\text { Technology/ } \\
\text { Application }\end{array}$ & $\begin{array}{l}\text { Range / } \\
\text { Accuracy }\end{array}$ & Advantages & Disadvantages \\
\hline $\begin{array}{l}\text { RF Positioning } \\
\text { (outdoor) }\end{array}$ & $\begin{array}{c}\text { Global / } \\
5 \mathrm{~m}\end{array}$ & $\begin{array}{l}\text { Accurate over } \\
\text { large areas }\end{array}$ & Only outdoors \\
\hline $\begin{array}{l}\text { RF Positioning } \\
\text { (indoor) }\end{array}$ & $\begin{array}{c}1 \mathrm{~km} / \\
1 \%\end{array}$ & $\begin{array}{l}\text { Underground } \\
\text { positioning }\end{array}$ & $\begin{array}{l}\text { Requires RF } \\
\text { infrastructure }\end{array}$ \\
\hline $\begin{array}{l}\text { Beacon sensors } \\
\text { (tracking) }\end{array}$ & $\begin{array}{l}200 \mathrm{~m} / \\
\text { Est: } 1 \mathrm{~m}\end{array}$ & $\begin{array}{l}\text { Tracking } \\
\text { through rock }\end{array}$ & $\begin{array}{l}\text { Large, active } \\
\text { beacons }\end{array}$ \\
\hline $\begin{array}{l}\text { RFID } \\
\text { (tracking) }\end{array}$ & $\begin{array}{c}10 \mathrm{~m} / \\
- \\
\end{array}$ & $\begin{array}{l}\text { Inexpensive } \\
\text { Simple to install }\end{array}$ & $\begin{array}{l}\text { Short range } \\
\text { No range info }\end{array}$ \\
\hline $\begin{array}{l}\text { Capacitive/Inductive } \\
\text { (proximity) }\end{array}$ & $\begin{array}{c}<100 \mathrm{~mm} / \\
-\end{array}$ & $\begin{array}{l}\text { Compact, } \\
\text { Simple to install }\end{array}$ & $\begin{array}{l}\text { Sensitive to } \\
\text { environment }\end{array}$ \\
\hline $\begin{array}{l}\text { Radar/Sonic/Optical } \\
\text { (proximity) }\end{array}$ & $\begin{array}{c}<100 \mathrm{~m} / \\
1 \%\end{array}$ & $\begin{array}{l}\text { Measure } \\
\text { distance\&speed }\end{array}$ & $\begin{array}{l}\text { Sensitive to } \\
\text { environment }\end{array}$ \\
\hline
\end{tabular}

information such as distance, approaching speed and temperature. Systems that are currently used in mining sites are mainly collision avoidance systems for automated vehicles based on electromagnetic sensors [1]. The main localization technologies used in mining are summarized in Table I.

\section{B. Imaging, 3D Ranging and Mapping}

Image and mapping sensors are in extensive use in the mining industry in a wide range of applications. These applications include site-local and remote surveillance of operations, equipment monitoring and control, and vehicle automation. They find mining-specific uses in large-scale topography and mapping, stockpile monitoring, cave evolution tracking, tonnage, rock face monitoring and particle measurement.

\section{1) Visual sensors}

Visual sensors are based on either CCD or CMOS sensors. They both operate based on electron excitation from incident photons, with the resulting charge representing light intensity. An optical filter is used to capture red, green and blue light separately. In CCD, each frame is extracted by sequential charge shifting from one pixel to the other by electrostatic gating. In CMOS sensors each pixel has a charge amplifier and is individually addressable. Although CCD was the technology that triggered the revolution in image acquisition in the 1990s, the two now compete in a range of applications and markets. CCD sensors are simple in implementation, allowing low cost as well as rapid advancement of pixel density, array size, etc., while CMOS is also low cost and provides lower power and faster operation, as well as an advantage in integration with silicon electronics. As a result of very high volume consumer markets, CMOS camera sensors for still or video images are available at very low cost and high pixel count. Their small size means they are compatible with very small optical systems, and that additional capabilities such as auto-focus, zoom, advanced stabilization and operation at very weak or very bright light conditions can be incorporated, enabling a powerful multifunctional system-level customization platform.

\section{2) Infrared sensors}

Infrared (IR) cameras have also benefitted from the recent imaging revolution. Their applications in mining include collision avoidance for vehicles and other mining equipment [12], vision in hindered lighting conditions, and equipment condition monitoring [13], including detection of hazards such as spontaneous combustion of coal [14]. The operating principle of an IR sensor is based either on thermal effects of incident infrared radiation, such as change of resistance, thermoelectric or pyroelectric effects or thermal expansion, or on electron excitation, using narrowband semiconductors. The latter are the most common in infrared imaging, providing high resolution. They typically require cooling modules to reduce self-heat induced noise. This reduces the portability of such devices and introduces a considerable burden of power consumption. Recently reported advances in low-bandgap semiconductors and super-lattice materials have allowed highresolution operation at higher temperatures [15]. Densely packed sensor arrays have enabled portable prototypes intended for military applications [16]. Furthermore, the FLIR ONE smartphone infrared camera model has introduced a simple and low cost portable infrared camera to the market, based on the combined processing of data from an infrared and a visible light camera sensor. In parallel, network-level optimization for energy demanding applications have been shown to extend the power autonomy of such systems [17]. We anticipate that these advances will lead to the ubiquitous use of compact industrial infrared imaging sensors, including wireless implementations.

\section{3) Depth sensors}

The rapid advancement of visual sensors between 2000 and today has provided the resources for various new device concepts. An evolution of particular interest is the emergence of depth sensors: devices that provide a three dimensional profile of an image. The main existing depth sensor technologies are time of flight (ToF) imaging [18], stereoscopic sensors, structured light technology [19] and light field cameras. ToF imaging involves the transmission and detection of modulated (infrared) light, phase shift measurement and translation to distance. Stereoscopic sensing involves the acquisition of an image from different angles and algorithmbased 3D reconstruction. The structured light technique is based on the transmission and detection of a pattern (e.g. infrared dots, stripes or multiple programmable patterns) and pattern-analysis based determination of depth [20]. An illustrative example of this approach is depicted in Fig. 2.

In light-field (plenoptic) camera technology, information of light direction is captured for every pixel by use of a microlens array. This information is subsequently used to extrapolate a 3D image of the depth profile, re-focus an image, etc. Recent advances involve new optical lens approaches, such as the combined use of a conventional lens and microlens to achieve directional capture at full resolution [21]. Manufacturers of such sensors include Raytrix GmbH and Lytro Inc..
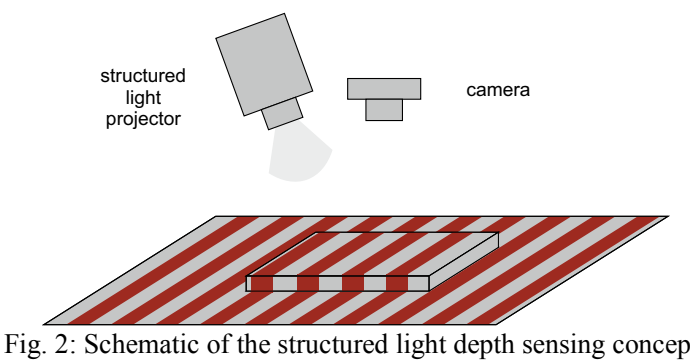
Laser equipment is typically used in hand-held custom ranging systems but also in remote mapping, especially for rock face profiling, where inaccessible locations may be involved. An example of a portable laser ranging device is the Laser Technology TruPulse 360 series, which measures slope distance and inclination, with integrated compass, GPS and Bluetooth capabilities.

\section{4) Three dimensional mapping}

Three dimensional mapping is based on the combination of optical and position/orientation sensors, sometimes complemented by other hardware such as depth and proximity detection, and spatial reconstruction software. Implementations range from triple-stereo satellite digital elevation models from Satellite Imaging Corp. to terrestrial laser-based site monitoring systems and hand-held indoor 3D mapping devices. Progress on hardware specifications such as angle of view, depth of field, resolution and orientation accuracy has played a significant role in the development of 3D mapping; however, in recent years the innovation front has shifted to signal processing. Merging of data acquired by multiple sensors into one 3D space model is a key aspect, as this can extract and provide the desired information from a large volume of raw data in real time, thereby reducing the cost of storage and transmission. An example of imaging re-combination is Immersive Media's 360 degrees Dodeca 2360 imaging system, which uses stitching algorithms to construct a full panoramic image of the surroundings of a single position, using cameras only. This is the system used to create Google Street View.

Another example can be found in Google's Project Tango, a 3D mapping system mainly for indoor locations. It is based on a combination of state-of-the-art optical, positioning, proximity and acceleration sensors with data recombination algorithms. The whole system fits comfortably in a smartphone-sized package. This development is expected to both reduce the cost and increase the performance of currently available small and medium scale 3D monitoring systems.

An important challenge in many automated navigation tasks is simultaneous localization and mapping (SLAM). In situations where both the local map and the precise location are not fully known, e.g. due to lack of sensor precision, software methods have been developed which increase the accuracy of both tasks by iterating the computation between the two. This has also been used in Google's Cartographer application for real time indoor mapping. It is anticipated that improvements in the performance of location and mapping sensors, and the ability to increase dramatically the number of such sensors, along with related technologies such as beacons, will make SLAM techniques considerably faster and more accurate, enabling the use of SLAM-guided automation in a wider range of tasks, especially higher speed ones. A comparative summary of the main 3D imaging technologies that are of interest to mining applications is given in Table II.

\section{Machine / Equipment Condition Monitoring}

Condition monitoring $(\mathrm{CM})$ is a key element of reducing downtime and improving the operational lifetime of machinery, through the optimized scheduling of preventative maintenance.
TABLE II

3D IMAging TECHNOLOGIES For Mining APPLICATIONS

\begin{tabular}{llll}
\hline \hline Technology & $\begin{array}{l}\text { Principle of } \\
\text { Operation }\end{array}$ & Advantages & Disadvantages \\
\hline $\begin{array}{l}\text { IR Time of flight } \\
\text { (ToF) }\end{array}$ & IR pulse ToF & mm-accurate & $\begin{array}{l}\text { High power, } \\
\text { low resolution }\end{array}$ \\
\hline $\begin{array}{l}\text { Stereoscopic } \\
\text { vison }\end{array}$ & $\begin{array}{l}\text { Two 2D sensors, } \\
\text { different angles }\end{array}$ & $\begin{array}{l}\text { No illumination } \\
\text { mm-accurate }\end{array}$ & $\begin{array}{l}\text { Limited range } \\
\text { s/w processing }\end{array}$ \\
\hline $\begin{array}{l}\text { Fixed structured } \\
\text { light }\end{array}$ & $\begin{array}{l}\text { Depth calculation } \\
\text { from distortion }\end{array}$ & mm-accurate & Short range \\
\hline $\begin{array}{l}\text { Programmable } \\
\text { structured light }\end{array}$ & $\begin{array}{l}\text { Depth calculation } \\
\text { from distortion }\end{array}$ & $\begin{array}{l}\mu \text { m-accurate, } \\
\text { high resolution }\end{array}$ & $\begin{array}{l}\text { Short range } \\
\text { SW processing }\end{array}$ \\
\hline $\begin{array}{l}\text { Light-field } \\
\text { camera(plenoptic) }\end{array}$ & $\begin{array}{l}\text { Light angle meas. } \\
\text { by pixel microlens }\end{array}$ & $\begin{array}{l}\text { No illumination } \\
\text { Image re-focus }\end{array}$ & $\begin{array}{l}\text { Lens array, } \\
\text { Reduced resol. }\end{array}$ \\
\hline $\begin{array}{l}\text { Laser 3D } \\
\text { mapping }\end{array}$ & $\begin{array}{l}\text { Laser pulse ToF }+ \\
\text { compass, position }\end{array}$ & $\begin{array}{l}\text { Long range, } \\
\text { mm-accurate }\end{array}$ & $\begin{array}{l}\text { Not real-time } \\
\text { Line-of-sight }\end{array}$ \\
\hline $\begin{array}{l}\text { 3D recombination } \\
\text { imaging }\end{array}$ & $\begin{array}{l}\text { Multiple images }+ \\
\text { compass, position }\end{array}$ & $\begin{array}{l}\text { Full mapping } \\
\text { Indoor-Outdoor }\end{array}$ & $\begin{array}{l}\text { Not real-time } \\
\text { s/w processing }\end{array}$ \\
\hline
\end{tabular}

Operational parameters and the usage of infrastructure is monitored by a wireless sensor network, which acquires and sends measurements to a data analysis center. Examples include the vibration signature, the strain and temperature history and the usage cycle of equipment and infrastructure. A decision making system is used to optimize maintenance, offering a powerful tool to the management of mining operations. Major mining equipment suppliers, including Caterpillar (Cat VIMS), Komatsu (Komtrax Plus Monitoring) and GE (STATEX), are already using telemetry systems to provide $\mathrm{CM}$ information locally (i.e. on board) and remotely (i.e. accessible from anywhere over the internet). Typically, a variety of embedded sensors are used to detect operational parameters such as engine speed, location, speed of movement, engine oil pressure, blowby pressure, fuel consumption rate, boost pressure and exhaust temperatures. These, combined with additional available information, such as service meter readings and number of operational hours per day, allow for an overall estimation of machines' health to be calculated. In aggregation, these can be used to effectively manage fleets of machines. A schematic description of the communication architecture of such a system is presented in Fig. 3, where the data flow of positioning and other monitoring technologies is also shown. It is possible that significant improvements over contemporary estimation-based $\mathrm{CM}$ techniques can be made by installing networked sensors capable of real-time condition monitoring that are much closer to specific phenomena of interest. Ultimately, this will allow extensions to the functional lifetime of assets, and optimization of down time and maintenance.

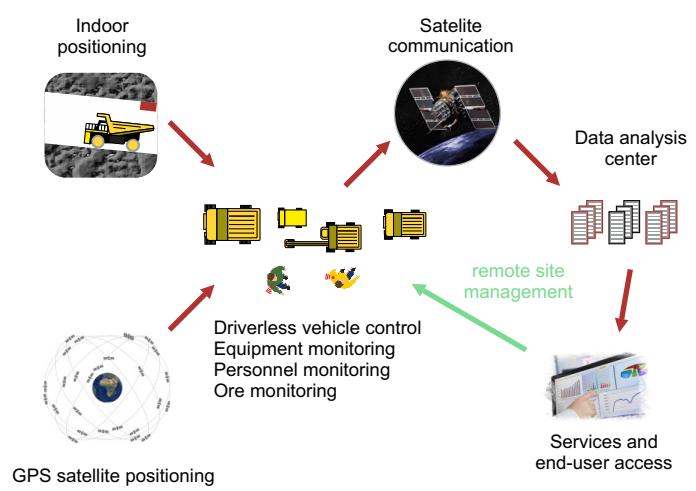

Fig. 3: Data flow of positioning and monitoring services in mining sites. 


\section{Composition Measurement}

The key application of composition analysis is in determining the elemental composition of ores during excavation (e.g. for drill positioning), processing (e.g. to control beneficiation equipment), and for sorting by ore grade during excavation, processing and transport.

Ore grade analysis is becoming increasingly more important and, at the same time, more challenging, due to the demand for lower-grade ore mining and processing. In particular, lowergrade ore mining and processing is becoming a necessity due to declining mine sites of sufficient quality to sustain the scale of typical mining operations (i.e. big shovels and big quantities). Established analytical methods for ore grade analysis, such as $\mathrm{X}$-ray Fluorescence (XRF) and X-ray Diffraction (XRD) currently mainly support laboratory analysis. However, handheld, on-site instruments for some analytical techniques are becoming available [22]. An example of laboratory based equipment is the QEMSCAN system, developed by CSIRO and supplied by FEI, which is based on combined Scanning Electron Microscopy (SEM) and Energy Dispersive X-Ray spectroscopy (EDX). Advances in micro-engineering have permitted the development of hand-held devices such as the miniature Mossbauer spectrometer, originally developed for NASA and now proposed for mining analysis [23]. Existing experience in the application of this type of sensor includes the analysis of ferrous rocks [24]. The use of micro-electromechanical systems (MEMS) techniques is enabling the development of portable mass spectrometers for a variety of applications in liquid, solid and gas analysis, offering the possibility of on-site mobile or pre-installed ore analysis solutions [25]. To date, these instruments are small enough for field deployment, but not sufficiently miniaturized. The next wave of development in materials analysis instruments will be towards miniature modules that can be directly installed in equipment such as diggers and drills, to allow real-time composition assessment.

A critical challenge in grade analysis is the determination of the actual grade from the material composition, because different materials, composites and concentrations behave differently during mineral processing. The analytical processing of composition in combination with existing databases has allowed automated mineralogy systems. Sensor based ore sorting and analysis advances have extended the amount of information that can be retrieved by ore sampling, providing a composition-depth profile [26]. So far these systems only use simpler sensor types (cameras and infrared spectroscopy) in combination with software analysis such as particle identification. Recently published results highlighting the application of a dual energy X-ray transmission array to runof-mine molybdenum ore sorting demonstrated recoveries of $66-93 \%$ and waste rejection of $40-94 \%$, with potential energy savings of $>60 \%$ due to waste rejection [27]. It is anticipated that, as compact and rugged systems come onto the market, they will permit the use of a wider range of measurement types. In turn, this may permit the enhancement of accuracy, automation and overall efficiency in ore sorting and analysis.
MineSense, for example, has brought to market systems capable of payload detection, including ore grade assessment, using high speed XRF and high frequency electromagnetic spectroscopy. Their ShovelSense product, which can be retrofitted to existing shovels, is capable of deciphering waste from ore in real time, in addition to quality analysis. This information, provided to the machine operator, allows the classified ore to be optimally loaded to waiting trucks.

The benefits of such real time ore grading systems include the minimization of ore type misallocation and ore dilution, opportunities to recover ore from waste, improve ore grade by reducing the mass of waste, and process performance improvements in leach and milling streams. Additional efficiencies may be achieved in energy consumption, whereby reduced crushing and grinding requirements contribute to significant savings, and in water conservation, where less water is required for concentration in the milling process. Integrated analytics over heterogeneous sensor data from extraction and haulage, with sensor data generated in processing (such as from air/gas mass flow meters that can be beneficial to improve flotation efficiency during froth phase, and hydrodynamic characteristics of pulp phase), could lead to more precise and efficient end-to-end product and systems management. In conclusion, a key challenge in mining is finding a way of exploiting smaller concentrations of high-grade ores efficiently. In this regime, real time ore grading systems have the potential to revolutionize mining with regard to precision processing and complementary resource efficiencies.

\section{E. Exploration}

A variety of sensing methods are employed for the discovery of new deposits. Because of the need to investigate large geographic expanses, remote detection methods, ideally deployable using aircraft, are preferred.

\section{1) Gravity gradiometry}

Gravity gradiometry has become a common technique for measuring variations of the Earth's gravitational acceleration. Its use in mining relates to the determination of the Earth's underground density profile which can indicate the presence of mineral deposits [28]. The sensor technology currently in broad use is based on differential measurements of tangential acceleration on a spinning disk, marketed by Lockheed Martin Corp. Other implementations have also been proposed for use in mining, such as the beam-balance VK-1 device of the University of Western Australia together with Rio Tinto [29]. Recently, new approaches such as the electrostatic gravity gradiometer (EGG) have been introduced, providing considerably higher accuracy. An EGG device was used by the European Space Agency GOCE mission, providing an accurate global gravity model, a global crust - mantle boundary (moho) profile and a range of secondary data and information. Currently a super-conducting implementation of further improved accuracy is being developed by ARKeX Instruments. Further research is focused on miniaturization at system level, combination with magnetic field mapping data and applicationspecific implementations [30]. 
TABLE III

GRAVITY GRAdIOMETRY SENSING SySTEMS USED IN Mining

\begin{tabular}{|c|c|c|c|}
\hline Technology & $\begin{array}{l}\text { Principle of } \\
\text { Operation }\end{array}$ & Features & $\begin{array}{l}\text { Development } \\
\text { Stage }\end{array}$ \\
\hline $\begin{array}{l}\text { Lockheed } \\
\text { Martin, GGI } \\
1986 \\
\end{array}$ & $\begin{array}{l}4 \text { tangential } \\
\text { accelerometers on } \\
\text { spinning disk }\end{array}$ & $\begin{array}{l}\text { Terrestrial } \\
\text { Noise*: } 15 \mathrm{E}^{2} / \mathrm{Hz} \\
\text { Size: } \sim 0.2 \mathrm{~m} \\
\end{array}$ & $\begin{array}{l}\text { Commercially } \\
\text { available }\end{array}$ \\
\hline $\begin{array}{l}\text { Falcon, GG } \\
1999\end{array}$ & $\begin{array}{l}8 \text { tangential } \\
\text { accelerometers on } \\
\text { spinning disk }\end{array}$ & $\begin{array}{l}\text { Airborne, High Res } \\
\text { Noise }<2 \mathrm{E}^{2} / \mathrm{Hz} \\
\text { Size: } \sim 0.4 \mathrm{~m} \\
\end{array}$ & $\begin{array}{l}\text { Commercially } \\
\text { available }\end{array}$ \\
\hline $\begin{array}{l}\text { VK-1, Univ. } \\
\text { Western } \\
\text { Australia } \\
\end{array}$ & $\begin{array}{l}\text { Orthog. Quad. } \\
\text { Responder/ beam } \\
\text { balance }\end{array}$ & $\begin{array}{l}\text { Air } \\
\text { Res:1 E/ } \sqrt{H z} \\
\text { Size: } \sim 0.5 \mathrm{~m}\end{array}$ & $\begin{array}{l}\text { Under } \\
\text { development }\end{array}$ \\
\hline $\begin{array}{l}\text { Electrostatic } \\
\text { GG }\end{array}$ & $\begin{array}{l}\text { 3D electrostatic } \\
\text { controlled } \\
\text { suspended mass } \\
\end{array}$ & $\begin{array}{l}\text { Satellite } \\
\text { Res: } 3 \mathrm{mE} / \sqrt{ } \mathrm{Hz} \\
\text { Weight: } 150 \mathrm{~kg} \\
\end{array}$ & $\begin{array}{l}\text { Under use by } \\
\text { the European } \\
\text { Space Agency }\end{array}$ \\
\hline $\begin{array}{l}\text { ARKeX, } \\
\text { Superconductin } \\
\text { g GG }\end{array}$ & $\begin{array}{l}\text { Mass suspended } \\
\text { by the Meissner } \\
\text { effect }\end{array}$ & $\begin{array}{l}\text { Airborne } \\
\text { Res: } 1 \mathrm{E} / \sqrt{ } \mathrm{Hz} \\
\text { Requires }-269^{\circ} \mathrm{C} \\
\end{array}$ & $\begin{array}{l}\text { Under } \\
\text { development }\end{array}$ \\
\hline Gravitec GG & $\begin{array}{l}\text { Deflection of } \\
\text { metal ribbon }\end{array}$ & $\begin{array}{l}\text { Borehole, Sens: } 5 \mathrm{E} \\
\text { Weight: } 1.3 \mathrm{~kg} \\
\text { Size: } 0.4 \mathrm{~m} \text { long }\end{array}$ & $\begin{array}{l}\text { Commercially } \\
\text { available }\end{array}$ \\
\hline $\begin{array}{l}\text { Atomic Interf. } \\
\text { GG, Stanford } \\
\text { University }\end{array}$ & $\begin{array}{l}\text { Laser-measured } \\
\text { difference of } \\
\text { atom trajectories }\end{array}$ & $\begin{array}{l}\text { Laser cooling } \\
\text { Bench size }\end{array}$ & Research \\
\hline
\end{tabular}

A summary of the main gravity gradiometry systems is presented in Table III. With decreasing size and power of exploration instruments such as these, a likely development is the increasing practicality of aerial surveys from low cost unmanned aircraft (drones). This will make regular re-mapping much more practical by greatly reducing costs.

\section{2) Time-lapse seismic monitoring}

Seismometers are usually designed to measure the low frequency, large amplitude motion of the Earth's crust, using an inertial mass suspended by a spring structure of wide frequency response. They are typically used in oil, gas and mining applications for estimating underground composition during exploration stages. Time-lapse seismic monitoring (4D seismic monitoring) refers to the continuous monitoring of seismic vibration towards a dynamic understanding of the behavior of a site. In its most popular implementation, the seismic response of a particular site is measured at the beginning and end of an extraction period. The difference between the two measurements corresponds to the composition change, allowing the monitoring of the deposit availability. Time-lapse seismic monitoring is therefore mainly used as a reservoir management tool [31]. Recent advances at the sensor level have allowed the measurement of micro-seismic activities with device sizes suitable for distributed installations. Such systems have enabled reservoir monitoring of excavation sites, cave/pit stability, detailed assessment of abnormal mine seismicity and seismic hazards, map caving front propagation, and induced seismic response [32]. In state-of-the-art micro-seismic sensors, important challenges include linearity of broadband response, rigidity, and reliability of operation in harsh environments. Recently, MEMS implementations have been successfully used in space exploration [33]. Such advances should allow cost effective implementation of distributed 4D seismic monitoring, including induced seismic responses, for mining applications.

\section{F. Health and Safety}

Health and Safety in the mining industry involves taking adequate measures and applying suitable policies to minimize the risk of accident occurrence, but also the risk of mid- and long-term health effects of exposure to hazardous environments. Policies already in place require regular examination of workers at risk [34]. This type of personnel monitoring involves standard outpatient-level hospital examination. On the other hand, the use of continuous monitoring of the location and health status of mine workers is under consideration by the mining industry. The concept of operation of these systems is based on wearable sensors, measuring parameters such as level of cumulative exposure to hazards (e.g. radiation or dust), heart-rate and blood oxygenation. The collected data are transmitted in real-time to an analysis server. Such a system could notably improve the efficiency of current Occupational Health and Safety Management Systems by providing early detection of risks and cutting overall policy costs.

\section{1) Personnel health monitoring}

Key challenges in the implementation of personnel health monitoring systems are the RF communication limitations in underground environments, comfort and practicality in usage, privacy issues and maintenance requirements mainly related to their power supply (e.g. battery change or recharge). General purpose, non-invasive, light and wearable sensors are already available for pulse, oxygenation, respiration and motion monitoring [35]. Products for monitoring individual persons are available and extensive research on their integration into multiple monitoring wireless sensor networks has been performed [36]. Commercial examples include the Alive Technologies Ltd Bluetooth heart and activity monitor, the Thermo Scientific Personal Dust Monitor 3700, the muscle activity sensors of Dorsavi's ViMove for work safety and the Firstbeat sport activity products. Whilst body-worn sensors such as those in smart watches and personal fitness monitors are becoming widespread, they are explicitly targeted at applications not requiring high reliability or accuracy.

\section{2) Fencing hazardous areas}

In hazard area fencing systems, wearable detectors can provide warning and trigger a preventive shutdown when an unsafe area is approached or entered (Fig. 4). These proximity sensors are typically electromagnetic. An example is the HASARD system, from the NIOSH Office of Mine Safety and Health Research [37]. Further information on proximity awareness and collision avoidance systems can be found in [38].

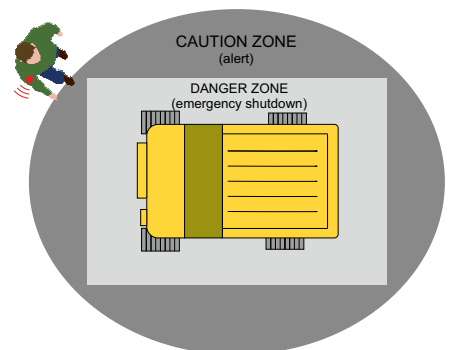

Fig. 4: Description of fencing hazardous areas by proximity sensing. 


\section{G. Tire Temperature and Pressure Monitoring Systems}

Tires are one of the top three operating expenses at a mine site, after fuel, accounting for $25-30 \%$ of haulage operating costs in quarries and open pit mines. Sub-optimally inflated tires can, for example, lead to an additional cost of 4-6\% in fuel. Tire temperature and pressure monitoring systems (TPMS) have the potential to improve safety, tire life, mine productivity and fuel efficiency. This has motivated a number of companies, including AM Bromley, Kal Tire, Valor and Schrader to produce TPMS solutions. Kal Tire, for example, has developed a patch comprising temperature and pressure sensors that is inserted in the tire, and communicates information in real time to the driver/operator, and beyond, using a range of wireless connectivity and visualisation options.

TPMS data may also allow analyses such as tire benchmarking, heat and weight surveys, site severity studies, road analysis and design, load area optimisation and payload monitoring. This can provide significant insight into, for example, cost benefit analyses across manufacturers and vehicle types, how to reduce load times, and tire stress and improve safety, and supply and demand forecasting over time.

\section{OUTLOOK}

\section{A. Exploration}

A key technology that will emerge in the next 2-5 years is continuously updated ore body modelling, driven by networked sensors operating at and near the ore face. Such systems include gravity gradiometry and seismic monitoring systems, and fielddeployable $\mathrm{x}$-ray and spectrometry ore analysis systems. This technology will provide direct and large-scale benefits in process efficiency, operating cost reduction and prediction and targeting of ore composition on a fine spatial scale.

Modelling of ore bodies using survey and other sensor data provides vital guidance on spatial variation of composition, such that high-grade locations can be targeted, guiding blasting and other extraction operations. Multi-parameter measurement during extraction can enable the continuous correction and updating of such models. These measurements include location, 3D imaging and mapping, and spatially resolved composition measurement of the ore face; and analysis of the geometry and composition of disrupted fragments, e.g. following each blast. Sensors can be deployed on vehicles, tools, and installations around the mining site. The resulting data can be relayed to an analytics center and used to continuously modify the models, enhancing their accuracy and resolution. Although such systems are already feasible to some extent, their effectiveness and practicality will increase rapidly in coming years as the relevant sensors become smaller, more rugged and integrated.

Integrated ore face measurement and modelling can provide online information about current and projected ore availability that can improve process and production planning. It will support extraction activities with optimized guidance on, for example, priority drilling areas to maximize the overall efficiency of operations. It will provide valuable ore grade data that can be used in combination with cave tracking analytics as feedback to correct deviations and adjust predictions. Finally, it will provide an overview of extraction evolution over time, which, in conjunction with corresponding productivity and cost indices, will form a valuable tool for the assessment of previous steps and current state, and decision support for subsequent action(s).

\section{B. Autonomous Wireless Sensor Networks}

The advantages of continuous monitoring go beyond maintenance optimization of equipment discussed in Section II.C. As seen in Figure 4, it applies to ore quality, safety and overall logistics optimization, which in coordination with the existing driver-less vehicle technology can lead to more reliable operation. As with condition monitoring however, a sensing system must itself require minimum maintenance. The availability and identification of the most suitable powering method for sensor nodes is key to this requirement. In this direction, recent advances in customized energy harvesting and wireless power delivery and recharging have broadened the available solutions [39]. This progress is expected to improve the profitability of continuous monitoring in the near future.

\section{Integrated Extraction and Processing}

Increasingly detailed and diverse data from the extraction process can improve efficiency, quality of ore recovered, and equipment lifetime, and be an aid to the planning of extraction operations. The same applies to subsequent processing, such as milling. However, further advantages will be obtained if the data from extraction is linked with that from processing. For example, the required time for milling and other factors, such as the energy input and optimum equipment settings, all depend on various characteristics of the ore to be processed. If relevant ore properties are known in advance, this will make process optimization easier and more effective compared to what can be achieved based solely on measurements within the processing machinery itself. By linking behavior during processing with parameters measured during (and before) extraction over many process cycles, and analyzing this data, a predictive capability can be developed linking the former to the latter.

The overall approach would be to measure ore face properties with high spatial resolution; extract from targeted locations; add additional measurement data from sensing during extraction; tag and track the extracted portions of ore during subsequent transport and delivery, in as small portions as practical; and link the associated data to additional measurements gathered during processing. Data analytics will then provide the correlations and other relationships between the various stages. Relevant sensing tasks would be ore face geometry (and geometry evolution) and composition, particle size and shape at all stages, ore portion location, and equipment parameters such as forces and motion of particular parts (e.g. shovel heads).

This can also enable a smarter approach to scheduling. It will allow estimation of processing speed and post-processed quality based on ore face characteristics so that the extraction process can be planned according to the final output demands. Thus, customer delivery-based scheduling can drive the whole extraction process, aiding prioritization and reducing delivery times, wastage and excessive stockpiling. 


\section{Linking Demand Chain with Supply Chain}

The integration between different stages of the mining process could be extended to linkages with customer operational data, allowing better targeted delivery to the customer. For example, the sintering process carried out at the beginning of steel production is highly dependent on the properties of the input ore. It can be optimized using measured data such as composition and particle size. If the delivered ore has been tracked in small portions all the way from initial ore face assessment, then the customer can be provided with a suitable subset of the associated data, which can be fed into their own subsequent optimization processes. This should enhance the performance of the customers' operations.

In addition, if customers are willing to share some data from their processes, mining companies can carry out analytics linking the ore characteristics all the way from the ore body assessment through to the customers' end products.

\section{CONCLUSION}

A summary of current and emerging sensing technologies that are significant to key future services in the mining industry is illustrated in Fig. 5. Accurate and widely available positioning will directly benefit exploration effectiveness, asset management, operations control and extend centralization. Ore grade monitoring is expected to allow more efficient mining from low grade deposits. The customization of integration and installation technologies to mining-specific operating conditions is expected to play a major role in the enabling of the aforementioned services. For this reason, closer cooperation between mining, networking, analytics and sensing industries will become a major advantage in developing a sustainable roadmap for mining operations.

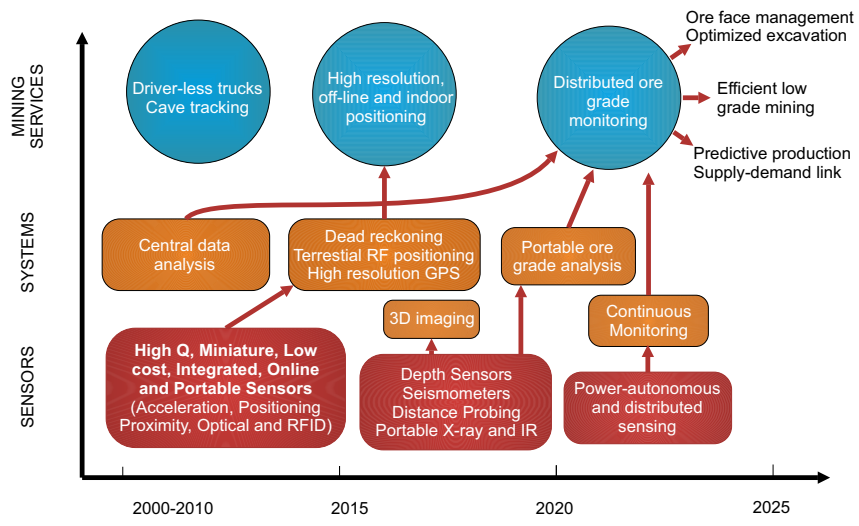

Fig. 5: The role of sensing technologies to key desirable mining services.

\section{REFERENCES}

[1] R. Spence, "Top Driverless Trucks in the Mining Industry Today Plus Future Concepts," Mining Global, 07 July 20142014.

[2] K. Diss, "Driverless trucks move all iron ore at Rio Tinto's Pilbara mines, in world first," 2015.

[3] J. A. Rodger, "Toward reducing failure risk in an integrated vehicle health maintenance system: A fuzzy multi-sensor data fusion Kalman filter approach for IVHMS," Exp. Syst. App. 39, 9821-2012.

[4] J. A. Rodger, "Application of a Fuzzy Feasibility Bayesian Probabilistic Estimation of supply chain backorder aging, unfilled backorders, and customer wait time using stochastic simulation with Markov blankets," Exp. Syst. App., vol. 41, pp. 7005-7022, 11/15/ 2014.
[5] NASA, Real-Time Tracking System Uses Ultra-Wideband RF Signals," 2012.

[6] K. Hlophe and F. du Plessis, "Implementation of an autonomous underground localization system," RobMech, 87-92, 2013

[7] "Scanning Range Sensor Performance for Mining Automation Applications," CRC Mining Latest News2014.

[8] E. Ruth, "Mining truck spotting under a shovel," Google Patents, 2014.

[9] D. Tadic, "CRCMining cave tracker system - pioneering flow monitoring for caving," AusIMM Bulletin, vol. 6, pp. 80-81, 2014.

[10] Apple iBeacons explained-smart home occupancy sensing solved? 2013.

[11] N. J. Lavigne, J. A. Marshall, U. Artan, and Ieee, " Towards underground mine drift mapping with RFID," 23rd Canadian Conference on Electrical and Computer Engineering, 2010.

[12] Avoiding accidents with mining vehicles [Online]. Available: http://www.flir.com/cs/emea/en/view/?id=51907

[13] S. Bagavathiappan, B. B. Lahiri, T. Saravanan, J. Philip, and T. Jayakumar, "Infrared thermography for condition monitoring - A review," Infrared Physics \& Technology, vol. 60, pp. 35-55, 2013.

[14] "FLIR cameras enable timely detection and localisation of selfcombusting coals," Australian Mining, 26 June, 2014.

[15] "Advances in detectors: Hot IR sensors improve IR camera size, weight, and power," Laser Focus World, 17 January 2014.

[16] D. Szondy, "DARPA developing personal LWIR cameras to give soldiers heat vision," 2013.

[17] M. Magno, D. Boyle, D. Brunelli, E. Popovici, and L. Benini, "Ensuring Survivability of Resource-Intensive Sensor Networks Through UltraLow Power Overlays," IEEE Trans. Ind. Inf., 10, pp. 946-956, 2014.

[18] L. Li, "Time-of-Flight Camera - An Introduction," Texas Instruments Technical White Paper, vol. SLOA190B, 2014.

[19] "3D Time of Flight Imaging Solutions," Texas Instruments 2014.

[20] J. Han, L. Shao, D. Xu, and J. Shotton, "Enhanced computer vision with microsoft kinect sensor: A review," 2013.

[21] M. Hiramoto, Y. Ishii, and Y. Monobe, "Light field image capture device and image sensor," ed: Google Patents, 2014.

[22] "XRF Analyzer and XRD Analyzer Solutions: Geochemistry and Mining," 2014

[23] "Miniature Mossbauer spectrometer. Applications to mining," 2014.

[24] R. V. Morris, G. Klingelhöfer, B. Bernhardt, C. Schröder, D. S. Rodionov, P. A. de Souza, et al., "Mineralogy at Gusev Crater from the Mössbauer Spectrometer on the Spirit Rover," Science, 305, 833, 2004.

[25] A. Malcolm, S. Wright, R. R. A. Syms, R. W. Moseley, S. O'Prey, N. Dash, et al., "A miniature mass spectrometer for liquid chromatography applications," Rap. Comm. Mass Spectr., 25, pp. 3281-3288, 2011.

[26] M. Dalm, M. W. N. Buxton, F. J. A. van Ruitenbeek, and J. H. L. Voncken, "Application of near-infrared spectroscopy to sensor based sorting of a porphyry copper ore," Minerals Eng., 58, pp. 7-16, Apr 2014.

[27] J. Lessard, J. d. Bakker, and L. McHugh. Development of ore sorting and its impact on mineral processing economics. Minerals Eng. 88, 2014

[28] M. Dransfield, "Airborne Gravity Gradiometry in the Search for Mineral Deposits," Advances in Airborne Geophysics, vol. 20, 2007.

[29] J. Anstie, T. Aravanis, M. Haederle, A. Mann, S. McIntosh, R. Smith, et al., "VK-1 - a new generation airborne gravity gradiometer," ASEG Extended Abstracts, vol. 2009, pp. 1-5, 2009.

[30] D. DiFrancesco, T. Meyer, A. Christensen, and D. FitzGerald, "Gravity gradiometry - today and tomorrow," 11th SAGA Biennial Technical Meeting and Exhibition, Swaziland, 2009.

[31] "4D Seismic Comes of Age," Offshore Technology2008.

[32] (2014). What is Microseismic Monitoring? Available: https://www.esgsolutions.com/english/view.asp? $\mathrm{x}=852$

[33] W. T. Pike, I. M. Standley, and S. Calcutt, "A silicon micro-seismometer for Mars," Transducers \& Eurosensors, 622, 2013

[34] "Health Monitoring in Mining Code of Practice," Safe Work Aust., 2011.

[35] S. Patel, H. Park, P. Bonato, L. Chan, and M. Rodgers, "A review of wearable sensors and systems with application in rehabilitation," $J$. Neuroeng. Rehab., vol. 9, p. 21, 2012

[36] A. Pantelopoulos and N. G. Bourbakis, "A survey on wearable sensorbased systems for health monitoring and prognosis," Trans. Sys. Man Cyber Part C, vol. 40, pp. 1-12, 2010.

[37] "HASARD - An Electromagnetic-Based Proximity Warning System " Office of Mine Safety and Health Research, 2014.

[38] D. Chirdon, "Proximity Detection / Collision Warning," Mine Safety and Health Administration, 2014.

[39] A. Costanzo, M. Dionigi, D. Masotti, M. Mongiardo, G. Monti, L. Tarricone, et al.,"Electromagnetic Energy Harvesting and Wireless Power Transmission:A Unified Approach,"Proc. IEEE, 102, 1692, 2014. 


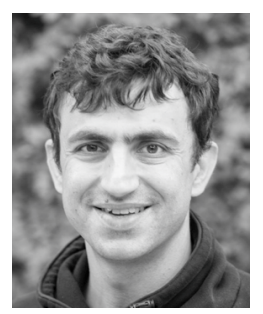

Michail E. Kiziroglou (Senior Member, IEEE) obtained his diploma in electrical and computer engineering from Aristotle University of Thessaloniki, Greece, in 2000 and his master in microelectronics and nanoelectronics from Democritus University of Thrace, Greece, in 2003. He holds a Ph.D. in microelectronics and spintronics awarded by the University of Southampton in 2007. $\mathrm{He}$ is a research associate with the Optical and Semiconductor Devices Group of Imperial College London. His research interests include energy harvesting devices, microengineering, and energy autonomous wireless sensors.

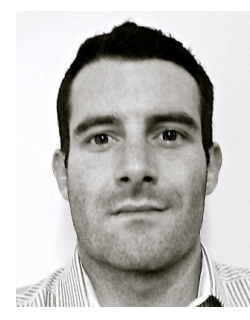

David E. Boyle (Member, IEEE) received the B.Eng. degree in computer engineering and Ph.D. degree in electronic and computer engineering from the University of Limerick, Limerick, Ireland, in 2005 and 2009, respectively. $\mathrm{He}$ joined the Department of Electrical and Electronic Engineering, Imperial College London, London, U.K., in 2012. His research interests span numerous topics within sensor networks, cyber-physical systems, and IoT technologies with industrial application.

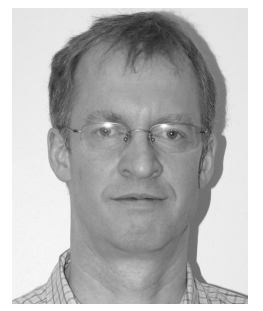

Eric M. Yeatman (Fellow, IEEE) obtained his B.Sc from Dalhousie University, Canada, in 1983, and his Ph.D. from Imperial College London in 1989 . He is currently a professor of micro-engineering and head of the electrical and electronic engineering department at Imperial College London. His research interests include motion and thermal energy harvesting for wireless devices, pervasive sensing, and sensor networks. He is a Fellow and Silver Medalist of the Royal Academy of Engineering, and is a cofounder and director of Microsaic Systems, which develops and markets miniature mass spectrometers for portable chemical analysis.

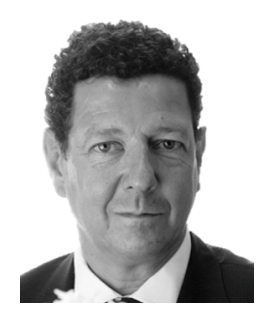

Jan J. Cilliers is Professor of Mineral Processing at the Royal School of Mines at Imperial College London. After studying Minerals Engineering, and working both underground and above on the South African gold and platinum mines, he did his $\mathrm{PhD}$ in Cape Town. His flotation research team uniquely specializes in the role of the froth in separating minerals. His research develops complex physical models and novel measurement techniques to improve mineral separations by design and control. In 2010 he was made a Fellow of the Royal Academy of Engineering. 